\title{
Iron-catalyzed benzylation of 1,3-dicarbonyl compounds by simple toluene derivatives
}

\author{
PAN ShiGuang, LIU JinHua, LI YuanMing \& LI ZhiPing* \\ Department of Chemistry, Renmin University of China, Beijing 100872, China
}

Received December 27, 2011; accepted March 17, 2012

\begin{abstract}
An iron-catalyzed oxidative $\mathrm{C}-\mathrm{C}$ bond formation by the reactions of simple toluene derivatives with 1,3 -dicarbonyl compounds is developed. A benzylic radical addition to a benzoylmethanato iron species is proposed for the transformation.

iron-catalyzed, benzylation, toluene derivatives, $\mathrm{C}-\mathrm{C}$ bond formation

Citation: $\quad$ Pan S G, Liu J H, Li Y M, et al. Iron-catalyzed benzylation of 1,3-dicarbonyl compounds by simple toluene derivatives. Chin Sci Bull, 2012, 57: 2382-2386, doi: 10.1007/s11434-012-5223-y
\end{abstract}

Direct $\mathrm{C}-\mathrm{H}$ bond functionalization presents an alternative pathway to traditional functional group transformation in modern organic synthesis [1-5]. The numerous advantages of $\mathrm{C}-\mathrm{H}$ bond transformation make it highly attractive for chemical synthesis. A great progress for $\mathrm{C}-\mathrm{H}$ bond functionalization has been made in the past decades [6-15]. However, only a few examples have been reported for the realm of simple $\mathrm{sp}^{3} \mathrm{C}-\mathrm{H}$ in the bulky compounds [16-23]. Since toluene derivatives were widely used in chemical industries, pharmaceuticals, and pesticides, it is highly desirable to develop a benzylation method using simple toluene derivatives.

Iron is one of the most abundant elements on earth and attracts much attention due to its low price and low toxicity. Accordingly, iron catalysis has been widely expanded in organic synthesis [24-31], and in particular, iron catalysts have resulted in great advances in the direct oxidation of $\mathrm{C}-\mathrm{H}$ bonds and $\mathrm{C}-\mathrm{C}$ bond formation [32-47]. We [48] reported an iron-catalyzed functionalization of benzylic $\mathrm{C}-\mathrm{H}$ bonds. Powell and coworkers [49] have also developed a conceptually similar, copper-catalyzed, $\mathrm{C}-\mathrm{C}$ bond formation by oxidative activation of benzylic $\mathrm{C}-\mathrm{H}$ bonds. However, toluene could not use as a substrate in the former case and exhibits very low reactivity in the latter. Therefore, the ex-

\footnotetext{
*Corresponding author (email: zhipingli@ruc.edu.cn)
}

tent of reactive benzylic $\mathrm{C}-\mathrm{H}$ bonds to simple toluene derivatives is one of great challenges in organic chemistry. Herein we wish to report our efforts toward functionalization of simple toluene derivatives using iron catalyst.

\section{Experimental}

\subsection{General information}

All reagents were weighed and handled in air and backfilled under $\mathrm{N}_{2}$ at room temperature. All reactions were conducted under a slightly positive pressure of nitrogen using standard Schlenk line techniques. Unless otherwise noted, all starting materials were commercially available and were used without further purification. ${ }^{1} \mathrm{H} \mathrm{NMR}$ and ${ }^{13} \mathrm{C}$ NMR spectra were recorded in parts per million $(\delta)$ relative to internal standard TMS (0) for $\mathrm{CDCl}_{3}$ and the internal solvent signals (central peak is 77.0 in $\mathrm{CDCl}_{3}$ ). The peak patterns are indicated as follows: s, singlet; d, doublet; dd, doublet of doublet; t, triplet; m, multiplet; q, quartet. The coupling constants, $J$, are reported in Hertz $(\mathrm{Hz})$.

\subsection{General procedure for products 3}

To a mixture of dibenzoyl methane $\mathbf{1 a}(0.5 \mathrm{mmol})$, toluene 2a $(1.0 \mathrm{~mL}, 9.0 \mathrm{mmol})$, and $\mathrm{Fe}(\mathrm{OAc})_{2}(0.05 \mathrm{mmol})$, di-tert- 
butyl peroxide $(2.0 \mathrm{mmol})$ was dropped into the mixture under nitrogen at room temperature. The tube was sealed and the resulting mixture was stirred at $120^{\circ} \mathrm{C}$ for $24 \mathrm{~h}$. The reaction temperature was cooled to room temperature. $\mathrm{K}_{4} \mathrm{Fe}(\mathrm{CN})_{6} \cdot 3 \mathrm{H}_{2} \mathrm{O}(40 \mathrm{mg}), \mathrm{HCl}(5 \%, 3.0 \mathrm{~mL})$, and $\mathrm{CH}_{2} \mathrm{Cl}_{2}$ $(3.0 \mathrm{~mL})$ were added sequentially and stirred until the organic layer turned into colorless. The resulting reaction solution was extracted with $4 \times 5 \mathrm{~mL}$ dichloromethane. The extract was washed with $2 \times 10 \mathrm{~mL}$ brine and dried over $\mathrm{MgSO}_{4}$. Solvent was evaporated and the residue was purified by flash column chromatography on silica gel with ethyl acetate/petroleum ether as eluent. 3a was obtained as colorless oil $(61 \%)$. ${ }^{1} \mathrm{H}$ NMR $\delta 7.89-7.87(\mathrm{~m}, 4 \mathrm{H}), 7.47(\mathrm{dd}$, $J=7.6,7.2 \mathrm{~Hz}, 2 \mathrm{H}), 7.34(\mathrm{dd}, J=8.0,7.2 \mathrm{~Hz}, 4 \mathrm{H}), 7.25-$ $7.17(\mathrm{~m}, 4 \mathrm{H}), 7.11(\mathrm{dd}, J=7.6,6.8 \mathrm{~Hz}, 1 \mathrm{H}), 5.57(\mathrm{t}, J=6.8 \mathrm{~Hz}$, $1 \mathrm{H}), 3.45(\mathrm{~d}, J=6.8 \mathrm{~Hz}, 2 \mathrm{H}) ;{ }^{13} \mathrm{C}$ NMR $\delta 195.3,138.9,135.8$, $133.3,128.1,128.7,128.4,128.4,126.4,58.7,35.1$; ATRFTIR $\left(\mathrm{cm}^{-1}\right)$ : 3064, 3038, 2907, 1694, 1667, 1595, 1497, 1350, 1271, 1236, 1182, 1001, 930, 758, 694, 608, 515; MS(EI) $m / z(\%): 317\left(\mathrm{M}^{+}\right), 209,149,131,105,91,77(100)$, 65, 51, 41, 37; HRMS(ESI) calcd. for $\mathrm{C}_{22} \mathrm{H}_{18} \mathrm{NaO}_{2}\left(\mathrm{M}^{+}+\mathrm{Na}\right)$ : 337.1199; found: 337.1196 .

\section{Optimization of the reaction conditions}

Dibenzoyl methane 1a and toluene 2a were chosen as the model substrates and tert-butyl peroxide, $(t \text {-BuO })_{2}$, was used as the oxidant to investigate the suitable reaction conditions (Table 1). The desired product 3a was obtained with $41 \%$ yield in the presence of 2 equiv of $(t-\mathrm{BuO})_{2}$ (Table 1 , entry 1). The yield of $\mathbf{3 a}$ was improved to $64 \%$ when 4 equiv of oxidant were applied (Table 1, entry 2). Importantly, the present transformation did not proceed at $80^{\circ} \mathrm{C}$ (Table 1 , entry 3), while reactive benzyl derivatives afford the corresponding oxidative coupling products smoothly [48]. The efficiency of this reaction dramatically decreased when $5 \mathrm{~mol} \%$ of catalyst was used (Table 1 , entry 4). Other organic peroxides were ineffective (Table 1, entries 5-7). Although $\mathrm{FeCl}_{3}$ led to a slight low yield of $\mathbf{3 a}$, comparable yields were obtained when $\mathrm{FeBr}_{2}, \mathrm{Fe}(\mathrm{OAc})_{2}, \mathrm{Fe}(\mathrm{acac})_{2}$, $\mathrm{Fe}(\mathrm{acac})_{3}$ and $\mathrm{Fe}_{2}(\mathrm{CO})_{9}$ were used as catalyst (Table 1, entries 8-13). Interestingly, 3a was formed with $12 \%$ yield even in the absence of iron catalyst (Table 1, entry 14). Moreover, TEMPO, a radical trapping reagent, completely suppressed this reaction (Table 1 , entry 15). These results indicated that a radical intermediate is most likely involved in the initial steps of the present transformation.

\section{The scope of the reactions}

The scope of the present transformation was investigated under the optimized reaction conditions (Table 2). paraXylene afforded the desired oxidative product $\mathbf{3 b}$ smoothly
Table 1 Optimization of the reaction conditions ${ }^{\text {a) }}$

\begin{tabular}{|c|c|c|c|}
\hline Entry & {$[\mathrm{Fe}](\mathrm{mol} \%)$} & [O] (equiv) & Yield $(\%)^{\mathrm{b})}$ \\
\hline 1 & $\mathrm{FeCl}_{2}(10)$ & $(t-\mathrm{BuO})_{2}(2)$ & 41 \\
\hline 2 & $\mathrm{FeCl}_{2}(10)$ & $(t-\mathrm{BuO})_{2}(4)$ & 64 \\
\hline 3 & $\mathrm{FeCl}_{2}(10)$ & $(t-\mathrm{BuO})_{2}(4)$ & N.D. ${ }^{\text {c) }}$ \\
\hline 4 & $\mathrm{FeCl}_{2}(5)$ & $(t-\mathrm{BuO})_{2}(4)$ & 21 \\
\hline 5 & $\mathrm{FeCl}_{2}(10)$ & $\mathrm{PhCOOO}-t-\mathrm{Bu}(4)$ & 9 \\
\hline 6 & $\mathrm{FeCl}_{2}(10)$ & $t-\mathrm{BuOOH}(4)^{\mathrm{d})}$ & 8 \\
\hline 7 & $\mathrm{FeCl}_{2}(10)$ & $\left(\mathrm{PhMe}_{2} \mathrm{CO}\right)_{2}(4)$ & 23 \\
\hline 8 & $\mathrm{FeCl}_{3}(10)$ & $(t-\mathrm{BuO})_{2}(4)$ & 49 \\
\hline 9 & $\mathrm{FeBr}_{2}(10)$ & $(t-\mathrm{BuO})_{2}(4)$ & 66 \\
\hline 10 & $\mathrm{Fe}(\mathrm{OAc})_{2}(10)$ & $(t-\mathrm{BuO})_{2}(4)$ & $72(61)$ \\
\hline 11 & $\mathrm{Fe}(\mathrm{acac})_{2}(10)$ & $(t-\mathrm{BuO})_{2}(4)$ & 67 \\
\hline 12 & $\mathrm{Fe}(\mathrm{acac})_{3}(10)$ & $(t-\mathrm{BuO})_{2}(4)$ & 67 \\
\hline 13 & $\mathrm{Fe}_{2}(\mathrm{CO})_{9}(5)$ & $(t-\mathrm{BuO})_{2}(4)$ & 62 \\
\hline 14 & & $(t-\mathrm{BuO})_{2}(4)$ & 12 \\
\hline 15 & $\mathrm{Fe}(\mathrm{OAc})_{2}(10)$ & $(t-\mathrm{BuO})_{2}(4)$ & N.D. ${ }^{\mathrm{e})}$ \\
\hline
\end{tabular}

a) Conditions: 1a $(0.5 \mathrm{mmol}), \mathbf{2 a}(1.0 \mathrm{~mL})$, under $\mathrm{N}_{2}$; unless otherwise noted. b) NMR yields are determined by ${ }^{1} \mathrm{H}$ NMR using $\mathrm{CH}_{2} \mathrm{Br}_{2}$ as an internal; the isolated yield is given in the parenthesis. c) Not detected by ${ }^{1} \mathrm{H}$ NMR; $80^{\circ} \mathrm{C}$. d) $5.5 \mathrm{~mol} / \mathrm{L}$ in decane. e) Not detected by ${ }^{1} \mathrm{H}$ NMR; TEMPO (1.0 mmol).

Table 2 The representative results ${ }^{\mathrm{a})}$

\begin{tabular}{cclcc} 
& & & \\
\hline
\end{tabular}

a) Conditions: 1 (0.5 mmol), $2(1.0 \mathrm{~mL})$, under $\mathrm{N}_{2}$; unless otherwise noted. b) NMR yields are determined by ${ }^{1} \mathrm{H}$ NMR using $\mathrm{CH}_{2} \mathrm{Br}_{2}$ as an internal; the isolated yield is given in the parenthesis. c) The $1: 1$ regioisomers. 
(Table 2, entry 1). However, meta- and ortho-xylene gave the corresponding products $\mathbf{3 c}$ and $\mathbf{3 d}$ with a decreasing yield compared with para-xylene (Table 2, entries 2 and 3). Moreover, a moderate yield of $\mathbf{3 e}$ was obtained when mesitylene was applied (Table 2, entry 4). These results indicated that the steric effect affected the efficiency of the reactions. Halogen and ester groups tolerated the present conditions and transformed into the desired products efficiently (Table 2, entries 5-7). In contrast, electron-withdrawing group decreased the yield of the reaction dramatically (Table 2, entry 8 ). This result suggested that the electronic effect also plays an important role. 2-Methyl naphthalene was a suitable substrate and the desired product was isolated in good yield (Table 2, entry 9). 2-Bromo-1,4-dimethylbenzene led to two regioisomers $3 \mathbf{k}$ with a $1: 1$ ratio (Table 2, entry 10). Other aromatic 1,3-diketones reacted efficiently with para-xylene (Table 2, entries 11 and 12). A 62\% yield of 3n was obtained when 1-phenylbutane-1,3-dione was used (Table 2, entry 13). $\beta$-Ketoester is unstable under the present reaction conditions and the transesterification product 3o' was obtained together with the desired product 30 (Table 2, entry 14).

\section{Mechanistic studies}

In order to assess the nature of charge development in the transition state of the reaction, a Hammett study was conducted by the relative reactivity of substituted toluenes (Figure 1). The Hammett slope $\rho$ was determined to be -0.31 for the reaction of dibenzoylmethane with substituted toluenes. The negative sign of $\rho$ reflects the fact that electron-donating substituent on the aromatic ring increase the reaction constant. On the other side, the small absolute value of $\rho$ often means that the mechanism of the reaction involves radical intermediates. Moreover, a linear correlation of $\lg k / k_{0}$ vs $\sigma$ implies that the position of the transition state is not changing as a result of a changing substituent.

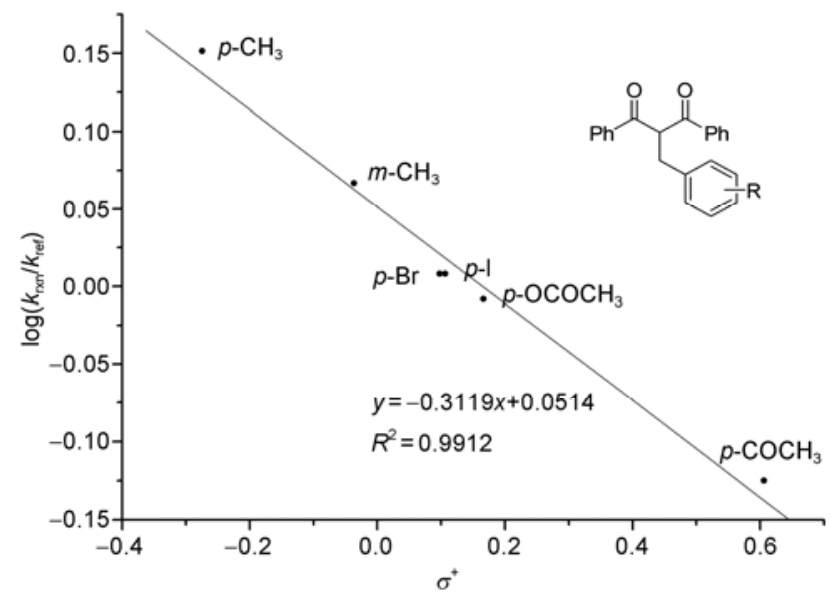

Figure 1 A Hammett plot.
Importantly, a certain amount of 1,2-diphenylethane 4 was obtained under the standard condition (eq. (1)). This result strongly supports a benzyl radical involving in the present transformation [50]. Furthermore, the competitive kinetic isotopic effect (KIE) experiments were carried out under the standard reaction conditions. The reaction shows a $k_{\mathrm{H}} / k_{\mathrm{D}}=8.0 \pm 0.1$. This significant isotopic effect indicates that the $\mathrm{C}-\mathrm{H}$ bond cleavage is the rate-determinating step of this transformation.

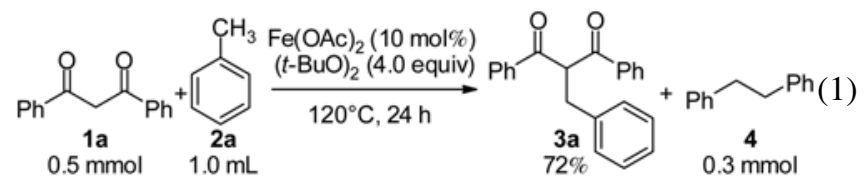

The roles of iron catalyst were also investigated (eqs. (2)(4)). A $63 \%$ yield of $\mathbf{3 b}$ was obtained in the presence of one third equiv of $\mathrm{Fe}(\mathrm{OAc})_{2}$ related to 1a (eq. (2)). Interestingly, a comparable yield was obtained using tri (dibenzoylmethanato) iron $\mathbf{5}, \mathrm{Fe}(\mathrm{dbm})_{3}$, instead of $\mathbf{1 a}$ in the absence of $\mathrm{Fe}(\mathrm{OAc})_{2}$ (eq. (3)). These results indicated that the formation of benzoylmethanato iron is likely involved in the present reaction. Importantly, the combination of $\mathrm{Fe}(\mathrm{dbm})_{3} \mathbf{5}$ and $\mathrm{Fe}(\mathrm{OAc})_{2}$ increased the yield of $\mathbf{3 b}$ to $84 \%$ (eq.(4)), which is similar to the result of entry 1 , Table 2 . The result demonstrated $\mathrm{Fe}(\mathrm{OAc})_{2}$ will also improve the efficiency of benzylic $\mathrm{C}-\mathrm{H}$ bond cleavage. Therefore, iron catalyst plays two roles in the present transform: (i) as a Lewis acid to activate 1,3-dicarbonyl substrates; (ii) as a redox catalyst to promote the decomposition of peroxide and thus improve hydrogen abstraction from benzylic $\mathrm{C}-\mathrm{H}$ bond.

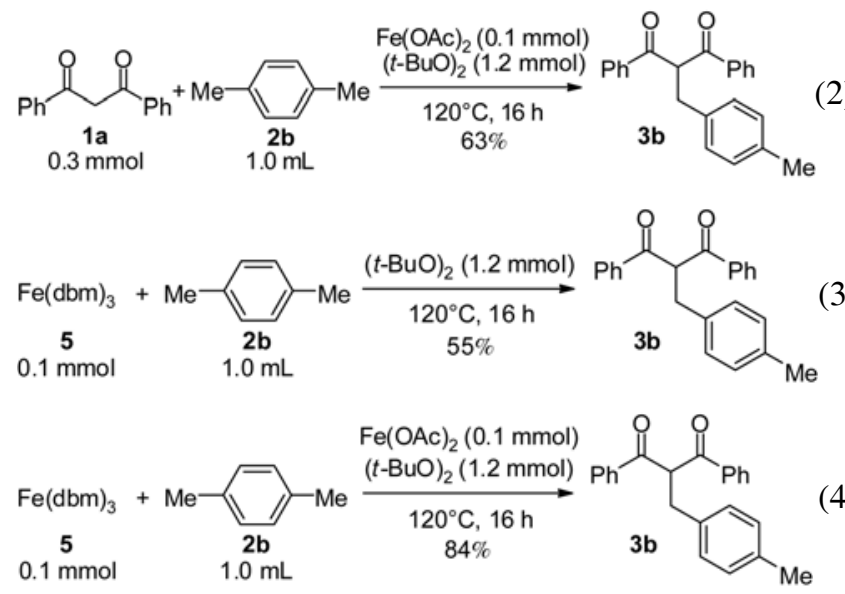

Based on the above results, a tentative mechanism for the iron-catalyzed functionalization of toluene derivatives is proposed (Scheme 1). tert-Butyl peroxide, $(t \text {-BuO })_{2}$, decomposes into tert-butoxyl radical and oxidizes $\mathrm{Fe}^{2+}$ to $\mathrm{Fe}^{3+}$. Then, a benzoylmethanato iron intermediate $\mathbf{A}$ is formed via a ligand exchange. On the other side, hydrogen abstraction by tert-butoxyl radical affords a benzylic radical, which is supported by the formation of 1,2-diphenylethane 4 . The radical addition of the benzylic radical to $\mathbf{A}$ followed by ferric oxidation provides the desired coupling product $\mathbf{3}$. 


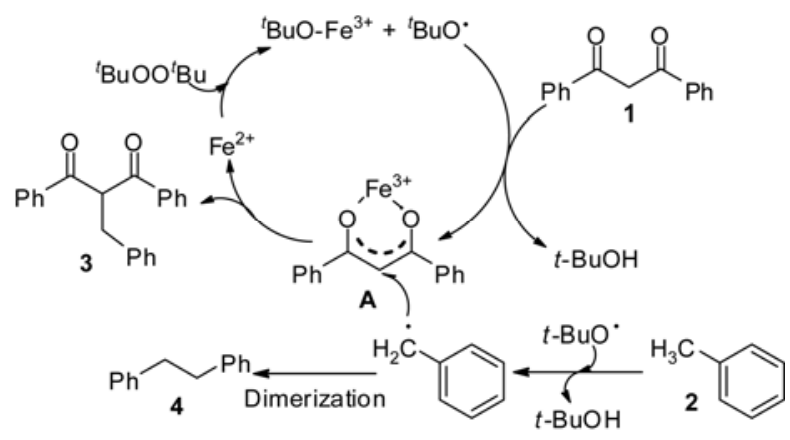

Scheme 1 A tentative mechanism.

Overall, the $\mathrm{Fe}^{2+}-\mathrm{Fe}^{3+}$ redox processes play key roles in the present $\mathrm{C}-\mathrm{C}$ bond formation, which are the reductive homolytic cleavage of $\mathrm{O}-\mathrm{O}$ bond in the peroxide and the oxidation of the carbon radical to oxonium.

\section{Conclusions}

In summary, we developed an iron-catalyzed oxidative coupling of simple toluene derivatives with 1,3-dicarbonyl compounds. The mechanistic studies demonstrated that the reactions proceed via a benzylic radical addition to a benzoylmethanato iron species. The applications of iron catalyst and simple toluenes are the advantages for organic synthesis.

This work was supported by the National Natural Science Foundation of China (20832002 and 21072223), the Fundamental Research Funds for the Central Universities, and the Research Funds of Renmin University of China (10XNL017).

1 Li C J. Cross-dehydrogenative coupling (CDC): Exploring $\mathrm{C}-\mathrm{C}$ bond formations beyond functional group transformations. Acc Chem Res, 2008, 42: 335-344

2 Li C J, Trost B M. Green chemistry for chemical synthesis. Proc Natl Acad Sci USA, 2008, 105: 13197-13202

3 Bergman R G. Organometallic chemistry: C-H activation. Nature, 2007, 446: 391-393

4 Chen H, Schlecht S, Semple T C, et al. Thermal, catalytic, regiospecific functionalization of alkanes. Science, 2000, 287: 1995-1997

5 Labinger J A, Bercaw J E. Understanding and exploiting $\mathrm{C}-\mathrm{H}$ bond activation. Nature, 2002, 417: 507-514

$6 \mathrm{Gu} \mathrm{S} \mathrm{J}$, Chen C, Chen W Z. Ortho-functionalization of 2-phenoxypyrimidines via palladium-catalyzed $\mathrm{C}-\mathrm{H}$ bond activation. J Org Chem, 2009, 74: 7203-7206

7 Powell D A, Fan H. Copper-catalyzed amination of primary benzylic $\mathrm{C}-\mathrm{H}$ bonds with primary and secondary sulfonamides. J Org Chem, 2010, 75: 2726-2729

$8 \mathrm{Li} \mathrm{H}$, Sun C L, Yu M, et al. The catalytic ability of various transition metals in the direct functionalization of aromatic $\mathrm{C}-\mathrm{H}$ bonds. Chem Eur J, 2011, 17: 3593-3597

9 Li B J, Yang S D, Shi Z J. Recent advances in direct arylation via palladium-catalyzed aromatic C-H activation. Synlett, 2008, 2008: 949

10 Dick A R, Sanford M S. Transition metal catalyzed oxidative functionalization of carbon-hydrogen bonds. Tetrahedron, 2006, 62: 2439-2463

11 Yu J Q, Giri R, Chen X. $\sigma$-Chelation-directed C-H functionalizations using $\mathrm{Pd}(\mathrm{II})$ and $\mathrm{Cu}(\mathrm{II})$ catalysts: Regioselectivity, stereoselectivity and catalytic turnover. Org Biomol Chem, 2006, 4: 4041-4047

12 Ritleng V, Sirlin C, Pfeffer M. Ru-, Rh-, and Pd-catalyzed C-C bond formation involving $\mathrm{C}-\mathrm{H}$ activation and addition on unsaturated substrates: Reactions and mechanistic aspects. Chem Rev, 2002, 102: 1731-1770

13 Dyker G. Handbook of $\mathrm{C}-\mathrm{H}$ Transformations. Weinheim, WileyVCH: 2005

14 Pan S, Liu J, Li H, et al. Iron-catalyzed $N$-alkylation of azoles via oxidation of $\mathrm{C}-\mathrm{H}$ bond adjacent to an oxygen atom. Org Lett, 2010, 12: 1932-1935

15 Qin C, Jiao N. Iron-facilitated direct oxidative C-H transformation of allylarenes or alkenes to alkenyl nitriles. J Am Chem Soc, 2010, 132: 15893-15895

16 Xia Q Q, Chen W Z, Qiu H Y. Direct C-N coupling of imidazoles and benzylic compounds via iron-catalyzed oxidative activation of C-H bonds. J Org Chem, 2011, 76: 7577-7582

17 Ueda M, Kondoh E, Ito $\mathrm{Y}$, et al. Benzyl radical addition reaction through the homolytic cleavage of a benzylic $\mathrm{C}-\mathrm{H}$ bond. Org Biomol Chem, 2011, 9: 2062-2064

18 Zhou W, Zhang L, Jiao N. Direct transformation of methyl arenes to aryl nitriles at room temperature. Angew Chem Int Ed, 2009, 48: 7094-7097

19 Ren H, Knochel P. Chemoselective benzylic C-H activations for the preparation of condensed $N$-heterocycles. Angew Chem Int Ed, 2006, 45: 3462-3465

20 Davies H M L, Jin Q, Ren P, et al. Catalytic asymmetric benzylic $\mathrm{C}-\mathrm{H}$ activation by means of carbenoid-induced $\mathrm{C}-\mathrm{H}$ insertions. J Org Chem, 2002, 67: 4165-4169

21 Okajima M, Soga K, Nokami T, et al. Oxidative generation of diarylcarbenium ion pools. Org Lett, 2006, 8: 5005-5007

22 Li Y Z, Li B J, Lu X Y, et al. Cross dehydrogenative arylation (CDA) of a benzylic $\mathrm{C}-\mathrm{H}$ bond with arenes by iron catalysis. Angew Chem Int Ed, 2009, 48: 3817-3820

23 Fan $\mathrm{R}, \mathrm{Li} \mathrm{W}, \mathrm{Pu} \mathrm{D}$, et al. Transition-metal-free intermolecular amination of $\mathrm{sp}^{3} \mathrm{C}-\mathrm{H}$ bonds with sulfonamides. Org Lett, 2009, 11: 1425-1428

24 Guan Z H, Yan Z Y, Ren Z H, et al. Preparation of indoles via iron catalyzed direct oxidative coupling. Chem Commun, 2010, 46: 2823-2825

25 Wang Y M, Bi X H, Li D H, et al. Iron-catalyzed synthesis of polysubstituted pyrroles via $[4 \mathrm{C}+1 \mathrm{~N}]$ cyclization of 4-acetylenic ketones with primary amines. Chem Commun, 2011, 47: 809-811

26 Wang Y M, Li W Q, Che G B, et al. Catalytic intramolecular aromatic $\mathrm{C}-\mathrm{H}$ alkenylation of arenes with non-activated ketones: Synthesis of 4-alkylene quinolin-2-ones. Chem Commun, 2010, 46: 6843-6845

27 Yang B L, Tian S K. Iron-catalyzed four-component reaction for the synthesis of protected primary amines. Eur J Org Chem, 2007, 46464650

$28 \mathrm{Li} \mathrm{H}, \mathrm{Li} \mathrm{W}$, Liu W, et al. An efficient and general iron-catalyzed C-C bond activation with 1,3-dicarbonyl units as a leaving groups. Angew Chem Int Ed, 2011, 50: 2975-2978

29 Zhang $\mathrm{Y}$, Li P, Wang L. Iron-catalyzed tandem reactions of aldehydes, terminal alkynes, and primary amines as a strategy for the synthesis of quinoline derivatives. J Heterocyclic Chem, 2011, 48: 153-157

30 Bolm C, Legros J, Le Paih J, et al. Iron-catalyzed reactions in organic synthesis. Chem Rev, 2004, 104: 6217-6254

31 Sun C L, Li B J, Shi Z J. Direct C-H transformation via iron catalysis. Chem Rev, 2011, 111: 1293-1314

32 Liu Z Q, Zhang Y X, Zhao L X, et al. Iron-catalyzed stereospecific olefin synthesis by direct coupling of alcohols and alkenes with alcohols. Org Lett, 2011, 13: 2208-2211

33 Bi H P, Chen W W, Liang Y M, et al. A novel iron-catalyzed decarboxylative $\mathrm{Csp}^{3}-\mathrm{Csp}^{2}$ coupling of proline derivatives and naphthol. Org Lett, 2009, 11: 3246-3249

34 Wang H, Wang L, Shang J, et al. Fe-catalysed oxidative C-H functionalization/C-S bond formation. Chem Commun, 2012, 48: 
$76-78$

35 Fürstner A, Leitner A, Méndez M, et al. Iron-catalyzed crosscoupling reactions. J Am Chem Soc, 2002, 124: 13856-13863

36 Bica K, Gaertner P. An iron-containing ionic liquid as recyclable catalyst for aryl grignard cross-coupling of alkyl halides. Org Lett, 2006, 8: 733-735

37 Hatakeyama T, Nakamura M. Iron-catalyzed selective biaryl coupling: Remarkable suppression of homocoupling by the fluoride anion. $\mathrm{J}$ Am Chem Soc, 2007, 129: 9844-9845

38 Li C Y, Wang X B, Sun X L, et al. Iron porphyrin-catalyzed olefination of ketenes with diazoacetate for the enantioselective synthesis of allenes. J Am Chem Soc, 2007, 129: 1494-1495

39 Fürstner A, Majima K, Martín R, et al. A cheap metal for a "noble" task: Preparative and mechanistic aspects of cycloisomerization and cycloaddition reactions catalyzed by low-valent iron complexes. J Am Chem Soc, 2008, 130: 1992-2004

40 Correa A, Garcia Mancheno O, Bolm C. Iron-catalysed carbonheteroatom and heteroatom-heteroatom bond forming processes. Chem Soc Rev, 2008, 37: 1108-1117

41 Stavropoulos P, Çelenligil-Çetin R, Tapper A E. The gif paradox. Acc Chem Res, 2001, 34: 745-752

42 Walling C. Intermediates in the reactions of fenton type reagents. Acc Chem Res, 1998, 31: 155-157
43 Zhang Y, Li C J. Highly efficient direct alkylation of activated methylene by cycloalkanes. Eur J Org Chem, 2007: 4654-4657

44 Chen M S, White M C. A predictably selective aliphatic C-H oxidation reaction for complex molecule synthesis. Science, 2007, 318: 783-787

45 Wang $\mathrm{Z}$, Zhang $\mathrm{Y}, \mathrm{Fu} \mathrm{H}$, et al. Efficient intermolecular ironcatalyzed amidation of $\mathrm{C}-\mathrm{H}$ bonds in the presence of $\mathrm{N}$-bromosuccinimide. Org Lett, 2008, 10: 1863-1866

46 Song C X, Cai G X, Farrell T R, et al. Direct functionalization of benzylic $\mathrm{C}-\mathrm{Hs}$ with vinyl acetates via $\mathrm{Fe}$-catalysis. Chem Commun, 2009: 6002-6004

47 He T, Yu L, Zhang L, et al. Direct C2-alkylation of azoles with alcohols and ethers through dehydrogenative cross-coupling under metal-free conditions. Org Lett, 2011, 13: 5016-5019

$48 \mathrm{Li} \mathrm{Z}$, Cao L, Li C J. $\mathrm{FeCl}_{2}$-catalyzed selective $\mathrm{C}-\mathrm{C}$ bond formation by oxidative activation of a benzylic $\mathrm{C}-\mathrm{H}$ bond. Angew Chem Int Ed, 2007, 46: 6505-6507

49 Borduas N, Powell D A. Copper-catalyzed oxidative coupling of benzylic $\mathrm{C}-\mathrm{H}$ bonds with 1,3-dicarbonyl compounds. J Org Chem, 2008, 73: 7822-7825

50 Protasiewicz J, Mendenhall G D. Di-tert-butyl hyponitrite as a source of alkoxyl radicals for dimerization. J Org Chem, 1985, 50: 32203222

Open Access This article is distributed under the terms of the Creative Commons Attribution License which permits any use, distribution, and reproduction in any medium, provided the original author(s) and source are credited. 